\title{
Geografía romántica. En busca del paisaje sublime
}

\author{
Tuan, Y. (2015). Geografía romántica. En busca del paisaje sublime. Madrid: Biblioteca Nueva.
}

\author{
Reseña elaborada por: Luis Guillermo Torres Pérez*
}

\begin{abstract}
Geografía romántica, más que una invitación a percibir un sentimiento idílico por el paisaje, es una oportunidad de reencuentro entre el ser humano consigo mismo y con el espacio. Desde la misma presentación que realiza el profesor Joan Nogué, el libro da cuenta de un viaje por aquellos lugares que, desde la experiencia y la subjetividad, evocan en los seres humanos sentimientos, motivaciones, temores, anhelos, entre otras sensaciones que hacen de la relación entre la humanidad y el espacio una experiencia sublime.
\end{abstract}

La obra que nos presenta Tuan transcurre a través de diferentes tipos de narraciones que involucran la disciplina geográfica, la literatura, el cine, los diarios de exploraciones, entre otros, que nos permiten viajar de un lugar a otro del planeta: desde los bosques de China hasta la selva tropical de América o de la resequedad del desierto hasta las alturas de las cumbres nevadas de las montañas. Tuan, al referenciar las obras de Homero, Shakespeare o las exploraciones Nansen y Shackleton, encuentra en estos tipos de narraciones un importante sustento de su obra ya que, citando sus propias palabras, "[...] es ahí donde la pasión adquiere su expresión más vívida" (p. 112). Así, el viaje propuesto por el autor involucra lo cotidiano, lo teórico y lo literario.

Pero más allá de la descripción, lo que hace de los paisajes lugares sublimes es la experiencia subjetiva e intersubjetiva que evoca en su relato al ubicar las emociones humanas y su ambivalencia en un punto preponderante en el análisis espacial y expresivo. La obra da cuenta de las cosmovisiones humanas en el tiempo y la cultura. Su narración nos transporta a las esferas del pasado y el presente, y a los terrenos de la cultura oriental y occidental, siendo parte de su propia experiencia histórica y relacional.

Estas características que han definido la obra de Yi-Fu Tuan hacen parte del enfoque humanista y fenomenológico de sus análisis, así Joan Nogué nos lo hace notar y nos invita a reconocer la experiencia, la subjetividad y la curiosidad presentes en la obra. Tuan se presenta como un ser magnético y humanista, cuyos fundamentos fenomenológicos permiten comprender la relación del ser humano con el lugar, concibiendo este último como un espacio existencial investido de significados, emociones, sentimientos, sensaciones y afectos, mostrándonos con ello un geógrafo apasionado por el paisaje, la imaginación y la realidad, y que en la narración de los viajes por los paisajes sublimes y ordinarios nos deja ver las intenciones y las relaciones de los seres humanos con el espacio geográfico.

En su obertura, Tuan indica cómo el romanticismo que quiere destacar se relaciona con el sentido heroico y admirable, propio de las exploraciones geográficas, incorporando lo que él denomina "una geografía imaginativa y atrevida pero anclada a la realidad" (p. 24), donde adquiere sentido lo cotidiano bajo una idea del sentir y del pensar. Así, lo romántico no busca "[...] tanto lo bonito o lo cáusticamente bello como lo sublime con su mezcla de cautivador y horrible, las alturas y las profundidades" (p. 26), lo que en esencia es el ser humano y el mismo espacio. Tuan advierte que el viaje que presenta

\footnotetext{
* Docente SED Bogotá y docente catedrático de la Universidad Pedagógica Nacional.
} 
se da en el marco de la sociedad occidental, en la que el romanticismo se ha eclipsado, a pesar de las pasiones, los deseos y las aspiraciones de los seres humanos.

En la primera parte, "Valores polarizados", Tuan nos propone analizar las construcciones binarias que han definido la cultura, la geografía y la cotidianidad misma. Establecer una polaridad entre la naturaleza y lo humano permite pensar en la dicotomía entre luz y tinieblas, caos y forma, lo alto y lo bajo, y la relación del cuerpo humano (razón y músculo) respecto al espacio y el estatus social. Estos conjuntos hacen ver las preferencias de los seres humanos por la luz (alejándose de lo desconocido de las tinieblas), el orden (plasmado en las estructuras cósmicas de las primeras ciudades), las alturas (propias de las élites) o la relación del cuerpo con las habitaciones, la jerarquía social y los oficios desempeñados (mostrando las esferas de lo público, lo privado, la obediencia y la supremacía de la razón). No obstante, lo que nos hace notar Tuan es cómo estos valores se pueden invertir, concibiendo, por ejemplo, lo claro como sinónimo de hipocresía o debilidad, y lo negro como símbolo de fertilidad y poder, o cómo en ciertos momentos quienes se encuentran en las alturas de la élite buscan encontrar significados en lo pequeño y en lo bajo.

Esta polaridad a la que hace referencia Tuan acompaña las narraciones de los paisajes románticos y sublimes, de forma que en la segunda parte, cuando el autor representa "La Tierra y sus entornos naturales", lo hace refiriéndose a ellos como una fuente de inspiración romántica desencadenada por el deseo de explorar los espacios inexorables que estimulan la imaginación, pero que generan cuestiones sobre el sustento, la estética y la moralidad. Así, por ejemplo, Tuan encuentra en el cambio de la concepción del geocentrismo al heliocentrismo una ruptura de la idea romántica de la perfección propia de una concepción esférica del sistema solar y de la Tierra. Del mismo modo y al interior del planeta, Tuan nos sumerge en los confines de las montañas, los mares, los bosques, los desiertos y los grandes bloques de hielo para ubicarnos en medio de un espacio imaginado donde abundan peligros, criaturas, condiciones adversas y maldad, espacios que adquieren otras denominaciones gracias al conocimiento que ofrecen los exploradores, convirtiéndose así en lugares de peregrinaje, sencillez, alejamiento mundano y motivación. Aquí se muestra cómo el momento histórico y cultural interviene en la visión del paisaje y cómo la atracción humana por la aventura, la exploración y el reconocimiento permiten concebir estos paisajes en el ámbito de lo imaginario, lo sublime y lo romántico, al tiempo que se convierten en lugares de encuentro subjetivo y con los sentimientos de arraigo por la vida y el hogar.

Como interludio, Tuan presenta una reflexión en torno a los espacios que generan seguridad, y la rebeldía que permite expandir la conciencia y buscar horizontes más allá del espacio conocido. En esta tarea recurre a los relatos del Génesis, los escritos de Hesíodo y las obras de Shakespeare, Anouilh y Wesker, para encontrar en sus personajes y diálogos el sustento de sus ideas.

En este recorrido Tuan nos pone frente a "la ciudad" como una manifestación de los ideales humanos de progreso, civilidad, protección, conquista, expresión, imaginación y racionalidad. El viaje por la ciudad propuesto inicia con la intención de crear un vínculo entre la tierra y el cielo a través de los centros rituales, la observación y la orientación de las estrellas. Con el tiempo la idea de la ciudad como ámbito urbano tiende a alejarse del espectro rural, sin embargo, Tuan nos hace ver cómo este vínculo nunca se rompe del todo, llevando a los seres humanos en la contemporaneidad a realizar prácticas agrícolas al interior de las urbes como una forma de mirar hacia el pasado en un acto romántico.

Tuan describe cómo las ciudades materializan los anhelos humanos por conquistar el clima y la noche, así las urbes se entienden como los lugares que protegen a los seres humanos de los fenómenos de la naturaleza. Para Tuan, la vida urbana y rural se desarrolla en una dicotomía entre el invierno y el verano, situación que genera migraciones entre estos dos espacios. Y así como el clima, la noche también se convirtió en una preocupación humana por muchos siglos, solventada tan solo con la invención de la electricidad, dando la posibilidad de percibir las ciudades como lugares seguros y sofisticados, lo que proporciona un nuevo sentido a la noche, uno más romántico. Por su parte, la dicotomía entre el cielo y el infierno se ve reflejada en la ciudad con la existencia de un mundo subterráneo y las historias que allí se plasman adquieren otra significación con el surgimiento del metro.

De esta forma, la ciudad al disipar la oscuridad da paso a la metáfora de cómo en las urbes se genera una dispersión de las tinieblas del intelecto y del espíritu a partir de diferentes formas de expresión, de tal forma que la palabra en las ciudades adquiere sentido desde la arquitectura, la literatura, la música y la vida misma, avivadas en las noches, momento en el que se despiertan las sensaciones humanas. Ante esta analogía, Tuan se remite a la ficción detectivesca de la obra de Doyle, viendo en el personaje de Holmes el anhelo humano de poseer la capacidad de adaptarse y orientarse en la sociedad y el espacio, lo que conlleva a una reflexión sobre el capitalismo, las tecnologías y las brechas entre ricos y pobres, disfunciones que se pueden enfrentar con educación en su sentido romántico.

En un cuarto apartado, Yi-Fu Tuan nos habla de "El ser humano", quien, interesado por la naturaleza, la cultura y sus transformaciones, construye sus historias personales impulsadas por las emociones e ideales más románticos. De allí se destacan tres tipos de seres humanos: el esteta, quien en el vitalismo de la vida, y se mueve entre la complejidad, la simpleza, lo corpóreo y lo espiritual de su propia cultura; el héroe, quien se enfrenta al peligro y se convierte en romántico al 
salir del comportamiento habitual salvando vidas o aventurándose en exploraciones que son asumidas socialmente como gestos de caballerosidad y sacrifico; finalmente, los santos, quienes en la Antigüedad se relacionaban con asuntos religiosos, en la actualidad se personifican con actos altruistas como la defensa de la naturaleza o la justicia social, materializando su sed por lo intangible y lo trascedente con una fuerte indiferencia a lo mundano.

Para finalizar, y como parte del coda de esta geografía romántica, Yi-Fu Tuan realiza una recapitulación de lo romántico y cómo el afán de la supervivencia del ser humano ha dejado de lado esta condición en el estudio de la geografía y de las ciencias sociales, de allí que realice un llamado a buscar que las motivaciones por el estudio del espacio se separen de lo económico y se relacionen con la existencia y la emoción. El llamado que hace Tuan es el de propender por una geografía para todos con trabajos dirigidos a lo común y a lo imaginativo, que sobrepasen el academicismo y las restricciones del lenguaje especializado, y se centren en valores en los que se expresan los temores y los deseos de los seres humanos.
Así, en Tuan el ser humano se ha enfrentado constantemente a la naturaleza y ha buscado cambiarla, primero con palabras, luego con herramientas y finalmente con construcciones como la ciudad, que a pesar de su carácter antinatural, se ha convertido en una realidad y un lugar que constituye al ser humano gracias a la imaginación y a los sentidos. Pensar en una geografía romántica nos remite a tener en cuenta que la vida es caótica por naturaleza, pero no por ello es alejada de la espontaneidad y la pasión. Por ello una geografía romántica actual debe separarse de las prácticas académicas de colección y de las ideologías de el momento:

[...] lo que se necesita para suplantar las tareas domésticas necesarias es una fuente romántica, trascendental, de compresión -lo que Wordsworth llama "un sentido de algo que está unido fuertemente, cuyo albergue es la luz de los ocasos" o la "música de las esferas" de Einstein-. Mientras que la "música de las esferas" hace tiempo que no está en boga en la física moderna, Einstein insinúa que, sin ella, y sin el oído para ella, no se puede llevar a cabo ningún trabajo científico realmente bueno. (p. 178). 